International Journal of Multidisciplinary Research AND ANALysis

ISSN[Online] : 2643-9875 || ISSN[Print] : 2643-9840

Volume 3 Issue 09 September 2020

DOI: 10.47191/ijmra/v3-i9-04, Impact Factor : 5.522

Page No : $94-98$

\title{
Clusters of Atoms of Copper and Irridium and Their Influence on Recombination Properties of Silicon
}

\author{
${ }^{1}$ Sherzod Axmadovich Mahmudov, ${ }^{2}$ Johongir Zokirjonovich Mirzaraimov, ${ }^{3}$ Avaz Karimjonovich Rafikov \\ 1,3 Institute of Nuclear Physics of the Academy of Sciences of the Republic of Uzbekistan \\ ${ }^{2}$ Namangan Technology and Engineering Institute
}

\begin{abstract}
The types and nature of structural defects of n-type silicon with clusters of impurity atoms of copper and iridium were determined by the method of non-stationary capacitive spectroscopy (DLTS), measurements of the resistivity, concentration and lifetime of charge carriers, as well as using infrared and atomic force microscopes Solver-NEXT. It was found that after hightemperature diffusion, star-shaped defects are observed in rapidly cooled $\mathrm{Si}<\mathrm{Cu}>$ samples, while in rapidly cooled Si <Ir> samples they are subsequently embedded in a chain and in the form of a needle, and in both slowly cooled samples, only roundshaped inclusions are formed, however, the density is low. The absence of dislocation decoration in slowly cooled $\mathrm{Si}<\mathrm{Cu}>$ and $\mathrm{Si}$ $<\mid r>$ samples is associated with the formation of point defects of the $\left[\mathrm{Cu}-\mathrm{O}\right.$ ] type, [Cu-Si] silicides, and pairs of $\mathrm{Cui}^{[}\left[\mathrm{Cu}_{\mathrm{s}}-\mathrm{Cu}_{i}\right]$ and Iri $\left[\mathrm{Ir}_{\mathrm{s}}-\mathrm{Ir} \mathrm{r}\right]$ atoms. An increase in the lifetime of charge carriers caused by the formation of an adhesion level associated with the $[\mathrm{Cu}-\mathrm{O}]$ complex in silicon.
\end{abstract}

KEYWORDS

Silicon, copper, iridium, oxygen, cluster, complex, defect, diffusion, cooling rate, lifetime, recombination properties

\section{INTRODUCTION}

The use of semiconductor crystals, in particular silicon, doped with fast-diffusing impurities, for the manufacture of microelectronic products largely depends on the presence of defects in the starting material. The main defects in silicon single crystals are dislocations, micro-defects, accumulations of impurity atoms in the form of clusters, precipitates, etc. [1]. The presence of such defects in silicon wafers can lead to a deterioration in the characteristics of the manufactured devices up to their failure. Therefore, the identification of these defects in crystals, the determination of their structure, properties, dimensions and concentration is of great practical importance. Despite the publications devoted to the study of the electrophysical, recombination and photoelectric properties of silicon doped with nickel impurities [2, 3], the formation of various structural defects in these materials and their rearrangement under external influences has not yet been studied.

The use of high-temperature diffusion with subsequent sharp cooling can be used to obtain nanoclusters of impurity atoms [4, 5]. At the same time, changing the diffusion temperature within $750 \ldots 1050^{\circ} \mathrm{C}$ and the cooling rate, it is possible to control the sizes of nanoclusters in the range of $10 \ldots 900 \mathrm{~nm}$. On this basis, in this work, the effect of the temperature of diffusion and isochronous annealing, as well as the cooling rates on the formation of clusters copper and iridium atoms in silicon.

\section{EXPERIMENTAL TECHNIQUE}

Silicon samples $\mathrm{n}-\mathrm{Si}\langle\mathrm{P}\rangle$ with a dislocation density of about $10^{4} \mathrm{~cm}^{-2}$ and an oxygen content of about $10^{17} \mathrm{~cm}^{-3}$, grown by the Czochralski method, with $\rho \approx 3 \mathrm{Om} \cdot \mathrm{cm}$ were cut in the form of a parallelepiped. Before alloying, the samples were processed mechanically and chemically. To carry out the diffusion of copper and iridium, metallic copper of $99.99 \%$ purity was sprayed on the cleaned surface of the samples in a vacuum, and an iridium solution was precipitated.

The alloying of silicon samples with copper and iridium was carried out by the thermal diffusion method in a horizontal furnace in quartz ampules at a temperature from 1050 to $1300{ }^{\circ} \mathrm{C}$ in an open volume for 5 hours. The diffusion temperature was controlled by a platinum-platinum-rhodium thermocouple. Diffusion cooling was carried out at different rates:

1 ) slow cooling in a furnace at a rate of $v_{o x l} \approx 30 \ldots 40$ grad / min - type I samples;

2) rapid cooling in air at a rate of $v_{o x l} \approx 250 \ldots 300 \mathrm{grad} / \mathrm{min}$ - type II samples. 


\section{Clusters Of Atoms Of Copper And Irridium And Their Influence On Recombination Properties Of Silicon}

To take into account the effect of heat treatment, the control samples were annealed under the same conditions without nickel impurity. Before investigating the properties to remove the damaged surface layer of silicon from all sides of the samples, nearsurface regions with a thickness of about $50 \mu \mathrm{m}$ were removed.

Structural defects in the obtained samples of $\mathrm{Si}<\mathrm{Cu}>$ and $\mathrm{Si}<\mathrm{Ir}\rangle$ were investigated using an infrared microscope, the surface of the samples - with an industrial atomic force microscope (ACM) Solver-NEXT, which makes it possible to measure the surface relief and potential distribution over the surface. The electrical and recombination properties were determined by measuring the resistivity $\rho$, the concentration of charge carriers $n$ by the Hall effect method, and the lifetime of minority charge carriers by the stationary photoconductivity method. To determine the energy of the levels and the concentration of impurity-defect centers, the method of non-stationary capacitive spectroscopy (DLTS) was used [6].

\section{EXPERIMENTAL RESULTS AND THEIR DISCUSSION}

In the DLTS spectra $\mathrm{n}-\mathrm{Si}<\mathrm{P}, \mathrm{Cu}>$ of type II samples (Fig. 1), two maxima are observed, $\mathrm{E}_{1}=\mathrm{E}_{\mathrm{c}}-<0.15 \pm 0.02 \mathrm{eV}\left(\sigma_{\mathrm{n}}=5 \cdot 10^{-14} \mathrm{~cm}^{2}\right.$ ) and $E_{2}=E_{c}-(0.22 \pm 0.02) \mathrm{eV}\left(\sigma n=6 \cdot 10^{-15} \mathrm{~cm}^{2}\right)$ after thermal diffusion at a temperature of $1150{ }^{\circ} \mathrm{C}$, in $\mathrm{n}-\mathrm{Si}\langle\mathrm{P}, \mathrm{Ir}>$ samples of types $I$ and II, three maxima are observed $E_{1}=E_{c}-(0.17 \pm 0.02) ; E_{2}=E_{c}-(0.33 \pm 0.02) ; E_{3}=E_{c}-(0.54 \pm 0.02)$; at a temperature of $1200{ }^{\circ} \mathrm{C}$. It should be noted that the concentration of the detected energy levels is no more than $5 \cdot 10^{13} \mathrm{~cm}^{-3}$ and depends on the diffusion temperature and rates of post-diffusion cooling. In $\mathrm{n}-\mathrm{Si}<\mathrm{P}, \mathrm{Cu}>$ samples of type $\mathrm{l}$, the concentration of these levels is 5-10 times lower than in samples of type II. The indicated energy levels were not observed on control samples. This means that the appearance of these centers is possibly associated with complexes of the type copper - uncontrolled impurity and iridium vacancy and iridium - uncontrolled impurity.

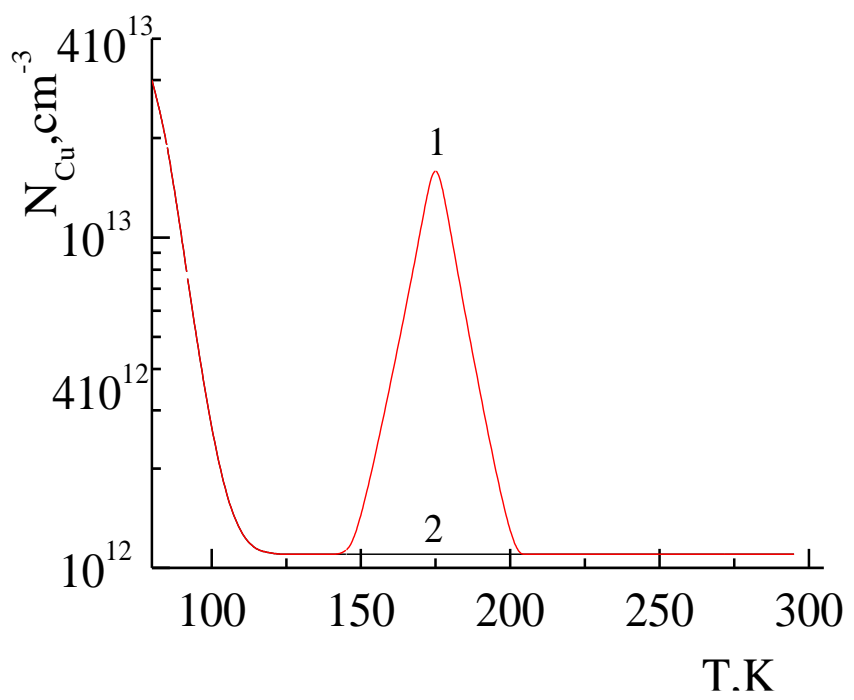

Figure: 1. DLTS spectrum n-Si $<P, C u>; 1$ - type II $E_{1}=E_{c}-(0.15 \pm 0.02)$ eV; $E_{2}=E_{c}-(0.22 \pm 0.02) e V ; 2-$ type I $E_{1}=E_{c}-$ $<0.15 \pm 0.02 \mathrm{eV}$; $\left(\mathrm{T}_{\text {dif. }}=1150^{\circ} \mathrm{C}\right)$.

Next, we studied the structure, size, and distribution of impurity defects in silicon doped with nickel. The results of studying the morphology of the surface relief of $\mathrm{n}-\mathrm{Si}<\mathrm{P}, \mathrm{Cu}>$ and $\mathrm{n}-\mathrm{Si}<\mathrm{P}, \mathrm{Ir}>$ samples obtained using ACM are shown in Fig. 2. In the surface region $\mathrm{n}-\mathrm{Si}<\mathrm{P}, \mathrm{Cu}>$ (Fig. 2, b), islands with a height of $\mathrm{h} \approx 160 \mathrm{~nm}$ and a width of $\mathrm{d} \approx 150 \mathrm{~nm}$ are formed, and in the surface region $\mathrm{n}-\mathrm{Si}<\mathrm{P}, \mathrm{Ir}>$ (Fig. $2, \mathrm{c}$ ) islands with a height of $\mathrm{h} \approx 40 \mathrm{~nm}$ and a width of $\mathrm{d} \approx 30 \mathrm{~nm}$ are formed.

The data obtained using ACM show that the nanoislands of honey and iridium in the solid solution $n-S i<P, C u>$ and $n-S i<P, I r>$ have a geometric dome shape, i.e., the so-called dome - islands with a characteristic lateral size $30 \ldots 160 \mathrm{~nm}$ with a round base (see Fig. 2, b and c). The appearance of such forms of honey and irid nanoislands is usually explained by the strong relaxation of elastic stresses in the configuration of the dome-phase. According to the data presented in [7], these nanoclusters are called hut-clusters with lateral sizes of $15 \ldots 25 \mathrm{~nm}$, they are absorbed by dome-clusters. This process is often accompanied by a bimodal size distribution of islands corresponding to the coexistence of hut and dome phases 

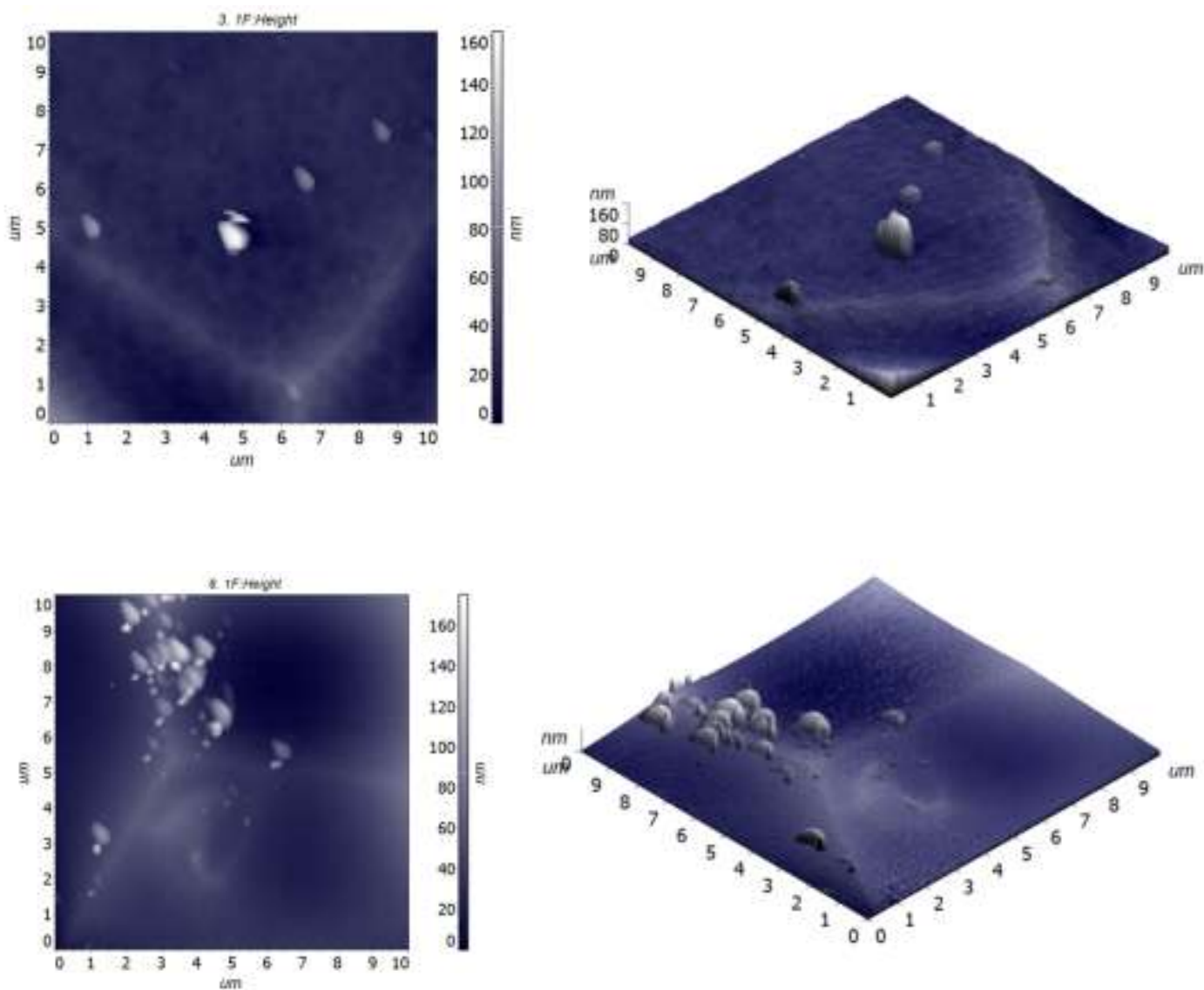

b

Figure: 2. Two-dimensional (a) and three-dimensional (b) images of the $\mathrm{n}-\mathrm{Si}<\mathrm{P}, \mathrm{Cu}>$ and $\mathrm{n}-\mathrm{Si}<\mathrm{P}$, Ir $>$ surfaces type II samples.

Micrographs of $\mathrm{Si}<\mathrm{Cu}>$ samples in which star-shaped defects are observed, which are numerous interconnected clusters of copper atoms in the form of six-and four-lobed rosettes, are shown in Fig. 3. and $\mathrm{Si}<\mathrm{Ir}\rangle$ in which needle-shaped defects are observed. The sizes of copper clusters reach $10 \ldots 35 \mu \mathrm{m}$, the sizes of iridium clusters reach $1 \ldots 5 \mu \mathrm{m}$, they are distributed over the volume of the crystal in the form of chains. Experiments show that the type and nature of the distribution of these structural defects in doped silicon play a decisive role in the formation of the electrophysical properties of doped silicon under external influences. For example, with a decrease in the size of clusters, the temperature and radiation stability of the electrophysical parameters $\mathrm{Si}<\mathrm{Cu}>$ increases, while $\mathrm{Si}<|r\rangle$, vice versa[5].

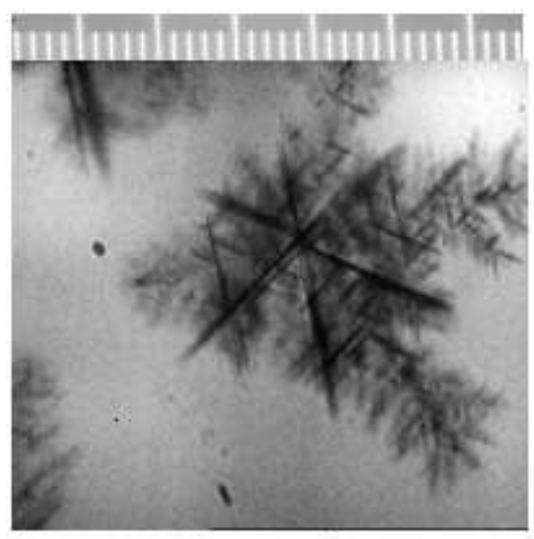

a)

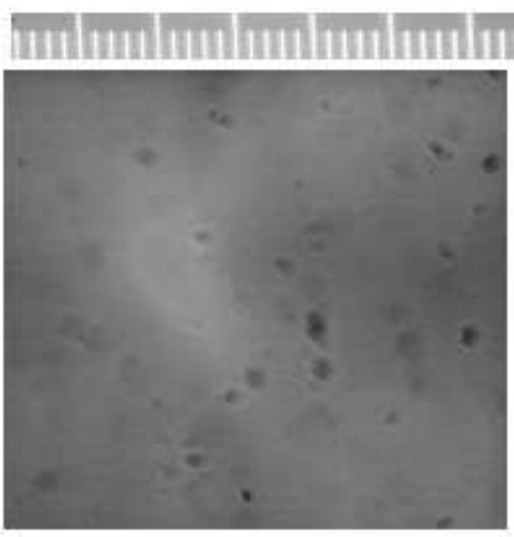

b

Figure: 3. Micrographs of copper-doped silicon samples with subsequent fast (a) and slow (b) cooling (micrometric scale with a step of $10 \mu \mathrm{km}$ ) 

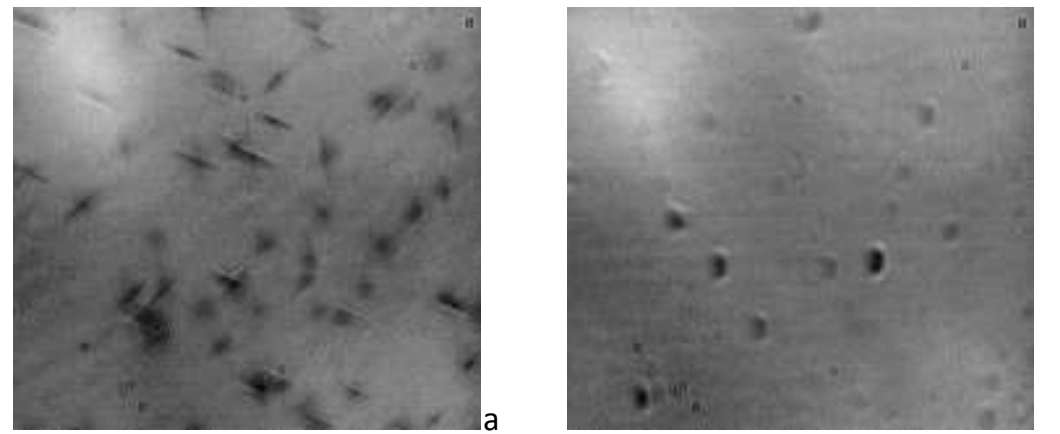

b

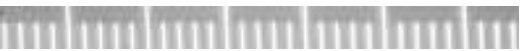

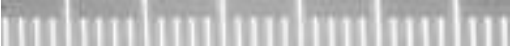

Micrographs of iridium-doped silicon samples with subsequent rapid (a) and slow (b) cooling (micrometric scale with a step of 10 $\mu \mathrm{km})$

A

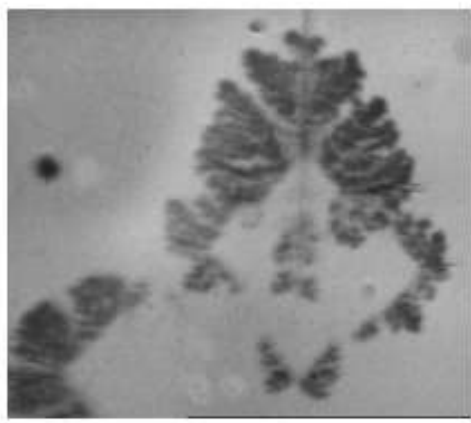

B

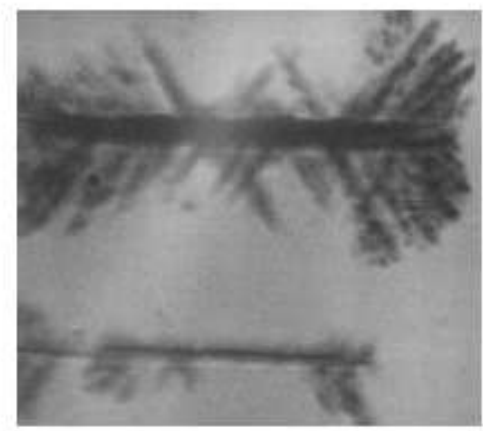

C

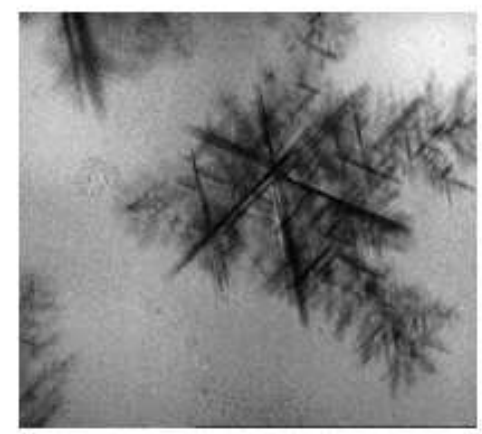

Figure: 4. Micrographs of variously oriented p-type silicon samples ( $\rho \approx 20 \mathrm{Om})$ doped with copper: a - <100>; b - <110>; c $<111>$ (the insets show a scale with a step of $10 \mu \mathrm{km}[9]$...

In doped silicon single crystals, the size of the forming defects was found to depend on the orientation of the grown crystal (Fig. 4). In this case, the introduction of a copper impurity into silicon leads to the formation of low-dimensional defective complexes with sizes of $10 \div 15 \mu \mathrm{m}$, with their subsequent incorporation, depending on the diffusion temperature, boron concentration and irradiation fluence, into multi-lobed compositions growing in the form of a tree (Fig. 3, 4), the sizes of which reach $70 \div 100 \mu \mathrm{m}$.

The effect of the concentration of copper and iridium atoms on the lifetime of minority charge carriers $\mathrm{n}-\mathrm{Si}<\mathrm{P},>$ and in samples of types I and II was studied, the results of which are given in the table. Analysis of the results shows that the lifetimes of minority charge carriers, first, are greater in $\mathrm{n}-\mathrm{Si}\langle\mathrm{P},>$ than in the control silicon sample, and secondly, with an increase in the concentration of copper and iridium atoms, the lifetime of minority charge carriers slightly increases ...

Lifetime of minority charge carriers in doped and control silicon samples with fast and slow cooling (types I and II)

\begin{tabular}{|c|c|c|c|c|c|c|}
\hline \multirow{3}{*}{ Тип образцов } & \multicolumn{6}{|l|}{$\mathrm{T}_{\mathrm{dif}},{ }^{\circ} \mathrm{C}$} \\
\hline & \multicolumn{2}{|l|}{1070} & \multicolumn{2}{|l|}{1120} & \multicolumn{2}{|l|}{1170} \\
\hline & I & II & 1 & II & $\mathrm{I}$ & II \\
\hline $\begin{array}{l}n-S i<P> \\
\left(\rho_{n}=3 \Omega \mathrm{CM}\right)\end{array}$ & $1 \cdot 10^{-7}$ & $1,4 \cdot 10^{-7}$ & $1 \cdot 10^{-7}$ & $1,4 \cdot 10^{-7}$ & $1,2 \cdot 10^{-7}$ & $1,3 \cdot 10^{-7}$ \\
\hline $\begin{array}{l}n-S i<P C u> \\
\left(\rho_{n}=3 \Omega \mathrm{cm}\right)\end{array}$ & $3 \cdot 10^{-6}$ & $3,7 \cdot 10^{-6}$ & $4 \cdot 10^{-6}$ & $5 \cdot 10^{-6}$ & $5,6 \cdot 10^{-6}$ & $6 \cdot 10^{-6}$ \\
\hline $\begin{array}{l}n-S i<P \mid r> \\
\left(\rho_{n}=3 \Omega \mathrm{cm}\right)\end{array}$ & $2,3 \cdot 10^{-5}$ & $3,5 \cdot 10^{-5}$ & $4,2 \cdot 10^{-5}$ & $5,8 \cdot 10^{-5}$ & $6,6 \cdot 10^{-5}$ & $8,8 \cdot 10^{-5}$ \\
\hline
\end{tabular}

If the concentration of the formed recombination centers in silicon is less than the concentration of sticking levels, then the total lifetime of minority charge carriers increases and is determined by the sticking levels. An increase in the lifetime of minority 


\section{Clusters Of Atoms Of Copper And Irridium And Their Influence On Recombination Properties Of Silicon}

charge carriers in doped samples as compared to the control one (see table) is possible, which is associated with the appearance of the E1 level caused by a point defect in silicon doped with copper, ie, with the formation of defects of the [Cu - O] type [8], which create adhesion levels for charge carriers. In addition, during the doping of silicon with a copper impurity, silicides [Si - O] also appear, which reduce the concentration of oxygen-containing recombination centers of the A-center type. It should be noted that, during cooling, the probability of the formation of a pair of $\mathrm{Cu}\left(\mathrm{Cu}_{s}-\mathrm{Cui}_{i}\right)$ atoms is low due to the weak binding energy of the copper atom at the lattice site. Therefore, the maximum observed values of the concentration of complexes of the $\left[\mathrm{V}-\mathrm{Cu}\right.$ ] type did not exceed $5 \cdot 10^{13} \mathrm{~cm}^{-3}$.

Experimental results on the determination of the state of impurity atoms and their clusters, the mechanisms of interaction with defects in the crystal structure of silicon, leading to the observed effects in the electrophysical and recombination properties of doped samples, the establishment of optimal technological conditions for the production of compensated silicon with specified properties provide thermal stability of the parameters of semiconductors and devices on their basis.

\section{CONCLUSION}

It is revealed that, during the formation of clusters of copper atoms in the bulk of silicon, star-shaped impurity-defect lowdimensional compositions are formed, having a layered distribution over the plane perpendicular to the direction of copper diffusion. Depending on the annealing temperature, an increase in the size of impurity-defect low-dimensional compositions can range from $10 \ldots 15$ to $30 \ldots 100$ microns.

It is shown that, during the formation of clusters of iridium atoms in the bulk of silicon, needle-shaped impurity-defect lowdimensional compositions are formed, having a layered distribution over the plane perpendicular to the direction of copper diffusion. Depending on the annealing temperature, the increase in the size of impurity-defect low-dimensional compositions can range from 5 to $30 \mathrm{mkm}$.

It was found that when silicon samples are doped with compensating impurities with an increase in the concentration of clusters of copper and iridium atoms, the lifetime of minority charge carriers increases. The observed anomalous effect is explained by the formation of various low-dimensional defect structures in the bulk of silicon, caused by nanocompositions of the impurity - oxygen and impurity - impurity type.

\section{REFERENCES}

1) Fistul V.I. Dopant atoms in semiconductors. Moscow, Fizmatlit, 2004.

2) Silva D. J., Wahl U., Correia J. G., et al. Drawing the geometry of $3 d$ transition metalboron pairs in silicon from electron emission channeling experiments. Nucl. Instrum. Instrum. Methods Phys. Res. B., 2016, vol. 371, pp. 59-62. DOI: 10.1016 / j.nimb.2015.09.051

3) Vyvenko O.F., Buonassisi T., Istratov A.A. X-ray beam induced current - a synchrotron radiation based technique for the in situ analysis of recombination properties and chemical nature of metal clusters in silicon. J. Appl. Phys., 2002, vol. 91, iss. 6, pp. 3614-3617. DOI: 10.1063 / 1.1450026

4) Riedel F., Schröter W. Electrical and structural properties of nanoscale NiSi2 precipitates in silicon. Phys. Rev. B, 2000, vol. 62, iss. 11, pp. 7150-7156. DOI: 10.1103 / PhysRevB.62.7150

5) Abdurakhmanov B.A., Bakhadirkhanov M.K., Ayupov K.S. Formation of clusters of impurity atoms of nickel in silicon and controlling their parameters. Nanosci. Nanotechnol., 2014, vol. 4, no. 2, pp. 23-26.

6) Schröter W., Hedemann H., Kveder V., et al. Measurements of energy spectra of extended defects. J. Phys .: Condens. Matter., 2002, vol. 14, no. 48, pp. 13047-13059. DOI: 10.1088 / 0953-8984 / 14/48/350

7) Lozovoy K.A. Kinetics of the formation of nanoheterostructures with germanium quantum dots on silicon for optoelectronic devices. Dis. ... Cand. physical-mat. sciences. Tomsk, TSU, 2016.

8) Istratov A.A., Weber E.R. Electrical properties and recombination activity of copper, nickel and cobalt in silicon. Appl. Phys. A, 1998, vol. 66, iss. 2, pp. 123-136. DOI: 10.1007 / s003390050649

9) Makhkamov Sh., Karimov M., Kurbanov A.O. and others. On the issue of thermal stability of the electrophysical properties $\mathrm{p}-\mathrm{Si}<\mathrm{P}, \mathrm{Ni}>$ and $\mathrm{p}-\mathrm{Si}<\mathrm{P}, \mathrm{Cu}>$. Proceedings of universities. Physics, 2005, No. 12, p. 80-82.

10) Tanaka S., Ikari T., Kitagawa H. In-diffusion and annealing processes of substitutional nickel atoms in dislocation-free silicon. Jpn. J. Appl. Phys., 2001, vol. 40, part 1, no. 5A, pp. 3063-3068. DOI: 10.1143 / JJAP.40.3063 